\title{
Degradation Dynamics and Residue Analysis of Flubendiamide in Cabbage and Soil by Liquid Chromatography-Tandem Mass Spectrometry with Dispersive Solid Phase Extraction
}

\author{
Xiaojun Chen*, Ping Wang, Zhiyuan Meng, Si Chen, Haotian Gu, Xiaoling Sha \\ School of Horticulture and Plant Protection, Yangzhou University, Yangzhou, China \\ Email: ${ }^{*}$ cxj@yzu.edu.cn
}

Received 22 June 2014; revised 24 July 2014; accepted 6 August 2014

Copyright (C) 2014 by authors and Scientific Research Publishing Inc.

This work is licensed under the Creative Commons Attribution International License (CC BY). http://creativecommons.org/licenses/by/4.0/

(c) (i) Open Access

\section{Abstract}

To formulate a scientific basis for a reasonable spray dose and safe interval period of $20 \%$ flubendiamide water dispersible granule (WDG) on controlling vegetable pests, degradation dynamics of flubendiamide in cabbage and soil was analyzed in this study. Dissipation and residue of flubendiamide in $20 \%$ flubendiamide WDG in cabbage and soil under field conditions were investigated by liquid chromatography-tandem mass spectrometry with dispersive solid phase extraction. Results showed that the degradation dynamic equations of flubendiamide in cabbage and soil were based on the first-order reaction dynamic equations. The half-lives of the degradation of flubendiamide were $3.51 \mathrm{~d}$ to $3.96 \mathrm{~d}$ and $3.43 \mathrm{~d}$ to $3.87 \mathrm{~d}$ in the cabbage of Yangzhou and Jingzhou, respectively, and $4.42 \mathrm{~d}$ to $5.13 \mathrm{~d}$ and $4.37 \mathrm{~d}$ to $4.99 \mathrm{~d}$ in the soil of Yangzhou and Jingzhou, respectively. The terminal residues of flubendiamide in the cabbage of Yangzhou and Jingzhou were $0.0247 \mathrm{mg} \cdot \mathrm{kg}^{-1}$ to $0.0393 \mathrm{mg} \cdot \mathrm{kg}^{-1}$ and $0.0225 \mathrm{mg} \cdot \mathrm{kg}^{-1}$ to $0.0273 \mathrm{mg} \cdot \mathrm{kg}^{-1}$, respectively, when $20 \%$ flubendiamide WDG was applied at a dose of $0.050 \mathrm{~g} \cdot \mathrm{m}^{-2}$. Flubendiamide is safe to be applied in cabbage fields at the recommended dose.

\section{Keywords}

Flubendiamide, Dispersive Solid Phase Extraction, LC-MS/MS, Degradation, Residue

\footnotetext{
${ }^{*}$ Corresponding author.
} 


\section{Introduction}

Flubendiamide is an inhibitor of ryanodine receptor that was developed by the Japanese Pesticide Corporation, Ltd. and first registered in the Philippines in 2007 [1] [2]. Flubendiamide is mainly effective for controlling lepidopteron pests, including resistant strains in vegetables, fruits, rice, and cotton. This insecticide has good, rapid, and long-term activity against both adults and larvae. Flubendiamide is a new phthalic amide insecticide that has a function in the activation mechanism of intracellular calcium release channels (ryanodine receptors), a leading cause of uncontrolled storage of calcium release. Given the uniqueness of this mechanism, no cross-resistance to conventional insecticides has been found, and it is safe for arthropods and mammals [1] [3]-[6]. The $20 \%$ flubendiamide water dispersible granule (WDG) is registered for controlling vegetable insects, such as Spodoptera exigua or Plutella xylostella, in China. In some reports, flubendiamide WDG is used to control rice pests. Flubendiamide is retained in cabbage after application in the field, and enters the soil and water system through a variety of ways. To date, reports on the detection and analysis methods of flubendiamide focus on the analysis of flubendiamide using HPLC-UV (UV-visible detector) and liquid chromatography-tandem mass spectrometry (LC-MS/MS) ion switching in the ESI position mode [7]-[14].

Field dissipation studies on pesticide persistence in foodstuff and behavior of pesticide residues in agricultural fields are necessary to ensure food safety and protection of the environment [15]. This study used the method based on LC-MS/MS in the ESI negative mode coupled with dispersive solid phase extraction method for identification and quantization of flubendiamide residues in 20\% flubendiamide WDG in cabbage and soil under field conditions. Experimental trials were conducted to determine and evaluate flubendiamide residue levels and dissipation rates in cabbage and soil under field conditions. The results can provide basic information to develop regulations on the safe use of flubendiamide in cabbage fields and to prevent any consumer health problems.<smiles>C=CC(=CC(C)=C(C=C)NC(=O)c1cccc(I)c1C(=O)NC(C)(C)CS(C)(=O)=O)C(F)(F)C(F)(F)C(F)(F)F</smiles>

Chemical structure of flubendiamide.

\section{Experimental Section}

\subsection{Equipments and Chemicals}

The instruments were BS210S electronic balance, SB-1000 rotary vacuum evaporator and THZ-82A vibrating machine made by Sartorius company of Germany, Eyela company of Japan and FuHua Company of Jiangsu province, China, respectively. Agilent 1200 Series HPLC system equipped with an Agilent 6460 Triple Quadrupole LC/MS system was made by Agilent Co. (USA).

Flubendiamide (purify 98.52\%) and flubendiamide WDG (20\%) were purchased from Fluka Company (USA) and Nihon Nohyaku Co. Ltd. (Japan), respectively. Dehydrated magnesium sulfate $\left(\mathrm{MgSO}_{4}\right)$, Primary secondary amine (PSA), and $\mathrm{C}_{18}$ were obtained from DIMA Technology, Inc., USA, and all of those were analytical grade. Methanol and acetonitrile were obtained from DIMA Technology, Inc., USA, and both were HPLC grade.

\subsection{Experiment Methods}

\subsubsection{Field Trials}

Field trials were conducted in Yangzhou City and Jingzhou City, China in 2011 and 2012. The tested plants were cabbage and its variety was Jiangfeng NO. 1. These trials were in accordance with the Guidelines on Pesticide Residue Trials [16] issued by the Ministry of Agriculture, People's Republic of China.

During the experimental period in 2011and 2012, rainfall events did not occur in Yangzhou and Jingzhou. In 2011, the average temperatures in Yangzhou and Jingzhou were $27.3^{\circ} \mathrm{C}$ and $28.1^{\circ} \mathrm{C}$, and the corresponding values for 2012 were $27.9^{\circ} \mathrm{C}$ and $28.3^{\circ} \mathrm{C}$, respectively. The experimental sites exhibit distinguishable soil properties. 
For example, the soil of Yangzhou is sandy clay loam with $18.5 \mathrm{~g} \cdot \mathrm{kg}^{-1}$ of organic matter and $\mathrm{pH}$ of 6.7, and the soil of Jingzhou is clay loam with $20.1 \mathrm{~g} \cdot \mathrm{kg}^{-1}$ of organic matter and $\mathrm{pH}$ of 6.5 .

Each experimental treatment consisted of three replicates and a control plot. A buffer area of $15 \mathrm{~m}^{2}$ separated each plot. To study flubendiamide dissipation in cabbage and soil, 20\% flubendiamide WDG was applied at 0.05 $\mathrm{g} \cdot \mathrm{m}^{-2}$ (twice the recommended dose).

To investigate the terminal residue of flubendiamide in cabbage and soil, 20\% flubendiamide WDG was applied at 0.025 and $0.05 \mathrm{~g} \cdot \mathrm{m}^{-2}$, representing the recommended dose and twice the recommended dose, respectively. Cabbage and soil samples were collected on $0,1,2,3,5,7$, and $10 \mathrm{~d}$ after spraying. The depth of the soil samples was $10 \mathrm{~cm}$. A minimum of $2 \mathrm{~kg}$ of cabbage was collected and homogenized with a blender on every sample from each plot. Soil samples $(1 \mathrm{~kg})$ were collected, mixed, and passed through a $1 \mathrm{~mm}$ sieve from each plot for analysis. All samples were stored at $-20^{\circ} \mathrm{C}$ prior to analysis.

\subsubsection{Dispersive Solid Phase Extraction Methods}

Cabbage and soil ( $5 \mathrm{~g}$ ) were weighed separately in a homogenate cup, and $30 \mathrm{~mL}$ of acetonitrile was added. After mashing the samples by a high-speed homogenizer for $3 \mathrm{~min}$, flubendiamide was added to the samples until the final concentrations of flubendiamide were 5.00, 1.00, and $0.20 \mu \mathrm{g} \cdot \mathrm{g}^{-1}$, respectively. A blank control group was also set up, and all experiments were repeated thrice. Then, $1.5 \mathrm{~g}$ of sodium chloride and $6 \mathrm{~g}$ of anhydrous magnesium sulfate were added in the samples prior to $5 \mathrm{~min}$ agitation in a rotary shaker at $4000 \mathrm{r} \cdot \mathrm{min}^{-1}$. About 2 $\mathrm{mL}$ of the upper mixture was collected, added to the centrifuge tubes containing $\mathrm{MgSO}_{4}(150 \mathrm{mg}$ ), PSA (25 mg), and $\mathrm{C}_{18}(25 \mathrm{mg})$, and agitated for $5 \mathrm{~min}$ in a rotary shaker at $4000 \mathrm{r} \cdot \mathrm{min}^{-1}$. The sample solution $(0.60 \mathrm{~mL})$ was diluted to $1.0 \mathrm{~mL}$ of distilled water. The sample solution was filtered through a $0.22 \mu \mathrm{m}$ membrane and subjected to LC-MS/MS chromatographic analysis in MRM mode.

\subsubsection{Determinations of Flubendiamide by LC-MS/MS}

The samples above were determinated and analyzed by LC-MS/MS. Determination method of flubendiamide in the cabbage was described by Chen et al. [17]. LC analysis was performed with an Agilent 1200 HPLC system equipped with a binary pump, auto plate-sampler, column oven, and diode-array detector. Separation was performed on Agilent Eclipse Plus chromatographic columns $C_{18}(4.6 \mathrm{~mm} \times 150 \mathrm{~mm}$ (i.d.), $5 \mu \mathrm{m})$ at $20^{\circ} \mathrm{C}$, with mobile solvents consisting of methanol: ammonium acetate with $1 \% 5 \mathrm{mmol} \cdot \mathrm{L}^{-1}$ acetic acid $=60: 40(\mathrm{~V}: \mathrm{V})$, isocratic at $1 \mathrm{~mL} \cdot \mathrm{min}^{-1}$. Aliquots of $5 \mu \mathrm{L}$ were injected directly to the LC-MS/MS system to test flubendiamide and quantified with external standard peak area. Mass spectra was recorded on an Agilent 6460 triple quadrupole (QQQ) mass spectrometer equipped with an ESI source. System control and data acquisition were controlled by Agilent Mass Hunter software. Detailed MS conditions were: cluster voltage: $-120 \mathrm{~V}$; gas temperature: $300^{\circ} \mathrm{C}$, gas flow $10 \mathrm{~L} \cdot \mathrm{min}^{-1}$, nebulizer pressure: $15 \mathrm{psi}$, sheath gas temperature: $250^{\circ} \mathrm{C}$; sheath gas flow: $7 \mathrm{~L} \cdot \mathrm{min}^{-1}$, capillary voltage: $4 \mathrm{kV}$, nozzle voltage: $500 \mathrm{~V}$. ESI was operated in the negative ion mode in the MRM (multiple reaction monitoring).

\subsubsection{Data Analysis}

The kinetic equation for degradation reactions of flubendiamide accorded to first-order kinetics:

$$
C_{t}=C_{0} \mathrm{e}^{-K t}, \quad T_{1 / 2}=\frac{\ln 2}{K}
$$

where $T_{1 / 2}$ was half life period of flubendiamide, $K$ was the first-order rate constant, $C_{0}$ was the initial concentration and $C_{t}$ was the flubendiamide concentration at time t.

\section{Results and Discussion}

\subsection{Results of Dispersive Solid Phase Extraction Methods}

The samples were allowed to settle for 30 min before using the extract and processed according to the aforementioned extraction procedure. To optimize the purification, different amounts of PSA $(0,10,25,50,75$, and 100 $\mathrm{mg})$ and $\mathrm{C}_{18}(0,10,25,50,75$, and $100 \mathrm{mg})$ were studied. The results showed no obvious improvement in the recovery of flubendiamide with increased amounts of PSA and $\mathrm{C}_{18}$. When $1 \mathrm{~mL}$ of the cabbage extract sample was purified with adsorbents (comprising $150 \mathrm{mg}$ of $\mathrm{MgSO}_{4}, 25 \mathrm{mg}$ of PSA, and $25 \mathrm{mg}$ of $\mathrm{C}_{18}$ ), pesticide loss decreased and impurities were eliminated. Therefore, $25 \mathrm{mg}$ of PSA, $25 \mathrm{mg}$ of $\mathrm{C}_{18}$, and $150 \mathrm{mg}$ of $\mathrm{MgSO}_{4}$ were 
needed for cabbage extract purification.

\subsection{Fortified Recoveries of Flubendiamide from the Cabbage and the Soil}

The fortified recoveries of flubendiamide from cabbage and soil were $80.70 \%$ to $90.44 \%$ and $84.37 \%$ to $94.00 \%$ as the coefficients of variation were $1.22 \%$ to $4.12 \%$ and $2.10 \%$ to $4.90 \%$, respectively. These values were in accordance to the pesticide residue criterion at different fortification levels (Table 1). According to the noise signal of LC-MS/MS, the lower limit of detection of flubendiamide was $0.015 \mathrm{mg} \cdot \mathrm{kg}^{-1}$.

\subsection{Degradation Dynamics of Flubendiamide in the Cabbage and Soil}

\subsubsection{Degradation Dynamics of Flubendiamide in the Cabbage}

Compared with the LC-MS/MS figure of flubendiamide standard, the LC-MS/MS figure of the cabbage sample exhibited intense ion fragmentation at $\mathrm{m} / \mathrm{z} 254,272,274$, and 214 in the MRM negative mode. The residue in the cabbage sample was proven to be flubendiamide (Figure 1 and Figure 2). The results showed that the degradation dynamic equations of flubendiamide in the cabbage were based on the first-order reaction dynamic equations, and the half-lives of the degradation of flubendiamide were $3.51 \mathrm{~d}$ to $3.96 \mathrm{~d}$ and $3.43 \mathrm{~d}$ to $3.87 \mathrm{~d}$ in the cabbage of Yangzhou and Jingzhou, respectively (Table 2).

Table 1. The recoveries of flubendiamide from the cabbage and the soil.

\begin{tabular}{ccccc}
\hline Sample & Fortification Levels $\left(\mathrm{mg} \cdot \mathrm{kg}^{-1}\right)$ & Average Recoveries (\%) & Standard Deviation & Coefficient of Variance (\%) \\
\hline \multirow{3}{*}{ Cabbage } & 5.0 & 90.44 & 0.0551 & 1.22 \\
& 1.0 & 89.83 & 0.0148 & 1.64 \\
& 0.2 & 80.70 & 0.0066 & 4.12 \\
Soil & 5.0 & 94.00 & 0.0988 & 2.10 \\
& 1.0 & 88.30 & 0.0260 & 2.95 \\
\hline
\end{tabular}

Note: Mean value of three replicates.

Table 2. Degradation dynamics equation of flubendiamide in the cabbage.

\begin{tabular}{cccc}
\hline Time (year) & Sample Location & Degradation Dynamics Equation & Correlation Coefficient \\
\hline \multirow{2}{*}{2011} & Yangzhou & $C_{t}=0.1865 \mathrm{e}^{-0.1750 \mathrm{t}}$ & 0.9812 \\
& Jingzhou & $C_{t}=0.1937 \mathrm{e}^{-0.1791 \mathrm{t}}$ & 0.9844 \\
2012 & Yangzhou & $C_{t}=0.2007 \mathrm{e}^{-0.1977 \mathrm{t}}$ & 0.9865 \\
& Jingzhou & $C_{t}=0.2106 \mathrm{e}^{-0.2021 \mathrm{t}}$ & 0.9783 \\
\hline
\end{tabular}

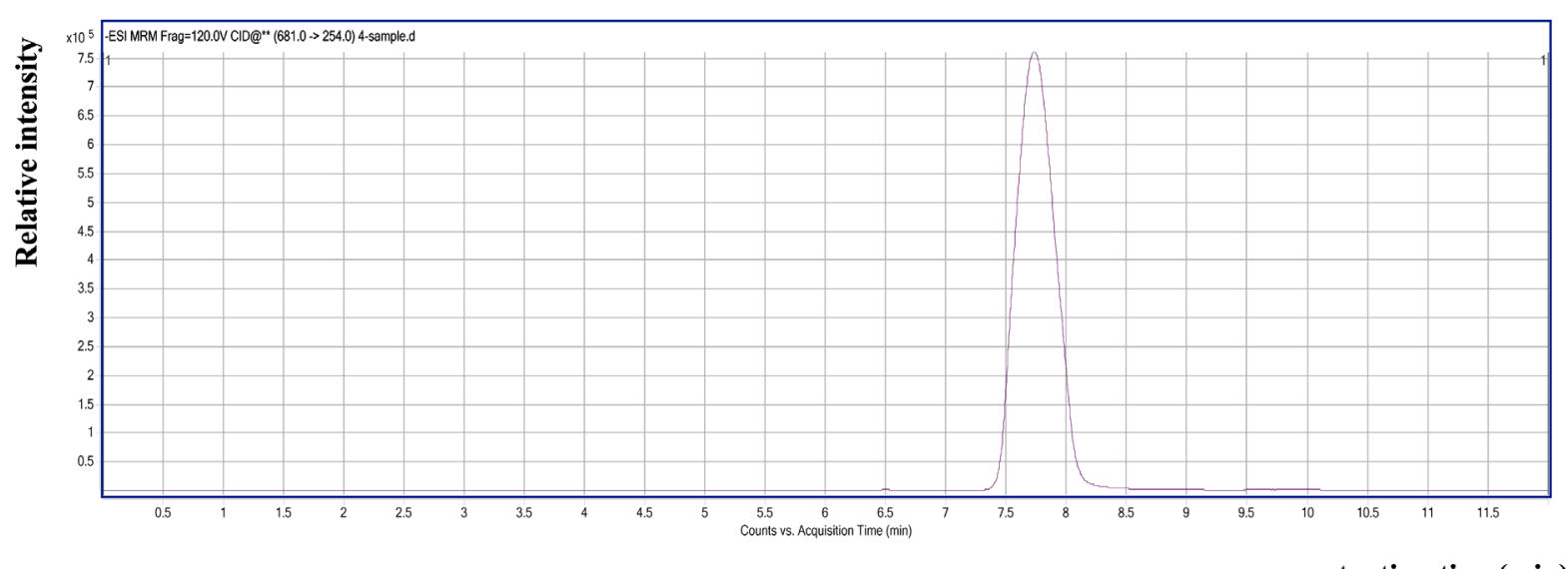

retention time(min)

Figure 1. Selected ionization chromatography of residual flubendiamide in the cabbage sample by MRM mode $(\mathrm{m} / \mathrm{z} 254)$. 


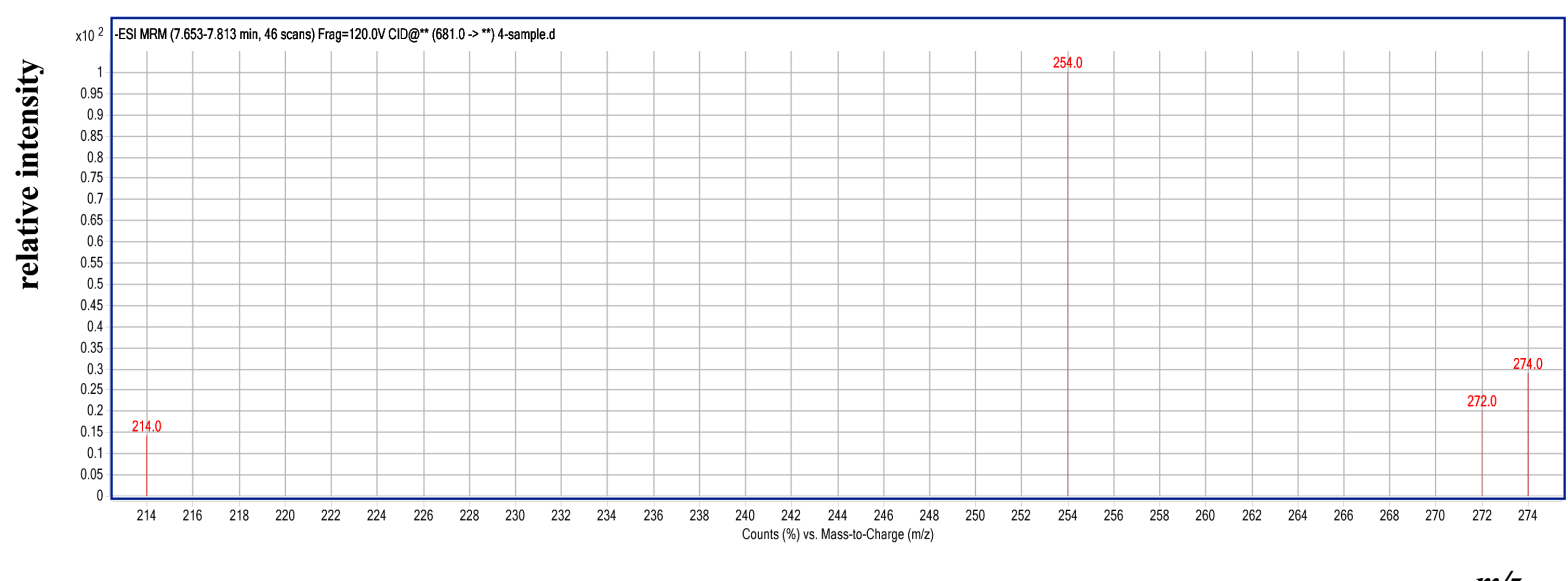

$m / z$

Figure 2. MS-MS spectrum of residual flubendiamide in the cabbage sample by LC-MS/MS.

\subsubsection{Degradation Dynamics of Flubendiamide in the Soil}

Compared with the LC-MS/MS figure of flubendiamide standard, the LC-MS/MS figure of the soil sample exhibited intense ion fragmentation at $\mathrm{m} / \mathrm{z} 254,272,274$, and 214 in the MRM negative mode. The residue in the soil sample was proven to be flubendiamide (Figure 3 and Figure 4). The results showed that the degradation dynamic equations of flubendiamide in the soil were based on the first-order reaction dynamic equations, and the half-lives of the degradation of flubendiamide were $4.42 \mathrm{~d}$ to $5.13 \mathrm{~d}$ and $4.37 \mathrm{~d}$ to $4.99 \mathrm{~d}$ in the soil of Yangzhou and Jingzhou, respectively (Table 3).

\subsection{Terminal Residue of Flubendiamide in the Cabbage and Soil}

\subsubsection{Terminal Residual of Flubendiamide in the Cabbage}

The terminal residue of flubendiamide in the cabbage of Yangzhou was not detected, but $0.0247 \mathrm{mg} \cdot \mathrm{kg}^{-1}$ to $0.0393 \mathrm{mg} \cdot \mathrm{kg}^{-1}$ was detected when $20 \%$ flubendiamide WDG was applied at concentrations of 0.0250 and 0.050 $\mathrm{g} \cdot \mathrm{m}^{-2}$. The terminal residue of flubendiamide in Jingzhou was not detected, but $0.0225 \mathrm{mg} \cdot \mathrm{kg}^{-1}$ to 0.0273 $\mathrm{mg} \cdot \mathrm{kg}^{-1}$ was detected when $20 \%$ flubendiamide WDG was applied at concentrations of 0.0250 and $0.050 \mathrm{~g} \cdot \mathrm{m}^{-2}$ (Table 4). The residue levels markedly lowered the MRL standard in the cabbage [MRL $=3 \mathrm{mg} \cdot \mathrm{kg}^{-1}$ (Japan); $\mathrm{MRL}=11 \mathrm{mg} \cdot \mathrm{kg}^{-1}$ (USA); MRL $=4 \mathrm{mg} \cdot \mathrm{kg}^{-1}$ (Australia)]. Harvest intervals were suggested to ensure that the cabbage was sufficiently safe for consumption at the recommended dose.

\subsubsection{Terminal Residual of Flubendiamide in the Soil}

The terminal residue of flubendiamide in the soil of Yangzhou was not detected, but $0.0691 \mathrm{mg} \cdot \mathrm{kg}^{-1}$ to 0.0762 $\mathrm{mg} \cdot \mathrm{kg}^{-1}$ was detected when $20 \%$ flubendiamide WDG was applied at concentrations of 0.0250 and $0.050 \mathrm{~g} \cdot \mathrm{m}^{-2}$. The terminal residue of flubendiamide in the soil of Jingzhou was not detected, but $0.0475 \mathrm{mg} \cdot \mathrm{kg}^{-1}$ to 0.0589 $\mathrm{mg} \cdot \mathrm{kg}^{-1}$ was detected when $20 \%$ flubendiamide WDG was applied at concentrations of 0.0250 and $0.050 \mathrm{~g} \cdot \mathrm{m}^{-2}$ (Table 5).

A number of techniques exist for the pretreatment of samples, including various solvent extraction methods, solid phase extraction or gel permeation chromatography clean up, followed by gas chromatography analysis using a variety of detectors [18]-[20]. Given that all these procedures are complex, require the use of toxic solvents, and are time consuming, an alternative technique called dispersive solid phase extraction was applied. This approach has wide analytical scope and high degree of selectivity and sensitivity. The method solves various problems, including low injection dosage, long analysis time and extensive use of poisonous solvents. Compared with other techniques, it has the following strong points: 1) As a multi-residue analytical method, it can reduce interferences from the sample matrix, such as chlorophyll, grease and moisture; 2) It has good stability and high recovery, and the recovery of numerous polar and volatile substances is over $85 \%$; 3 ) The analysis time is short as determination can be done in $10 \mathrm{~min}$ to $20 \mathrm{~min}$; 4) It uses a minimum amount of solvent, is inexpensive, and results in less pollution [21]-[23]. Dispersive solid phase extraction combined with LC- MS/MS method was applied in this study, according to the noise signal of LC-MS/MS, the lower limit of detection of 


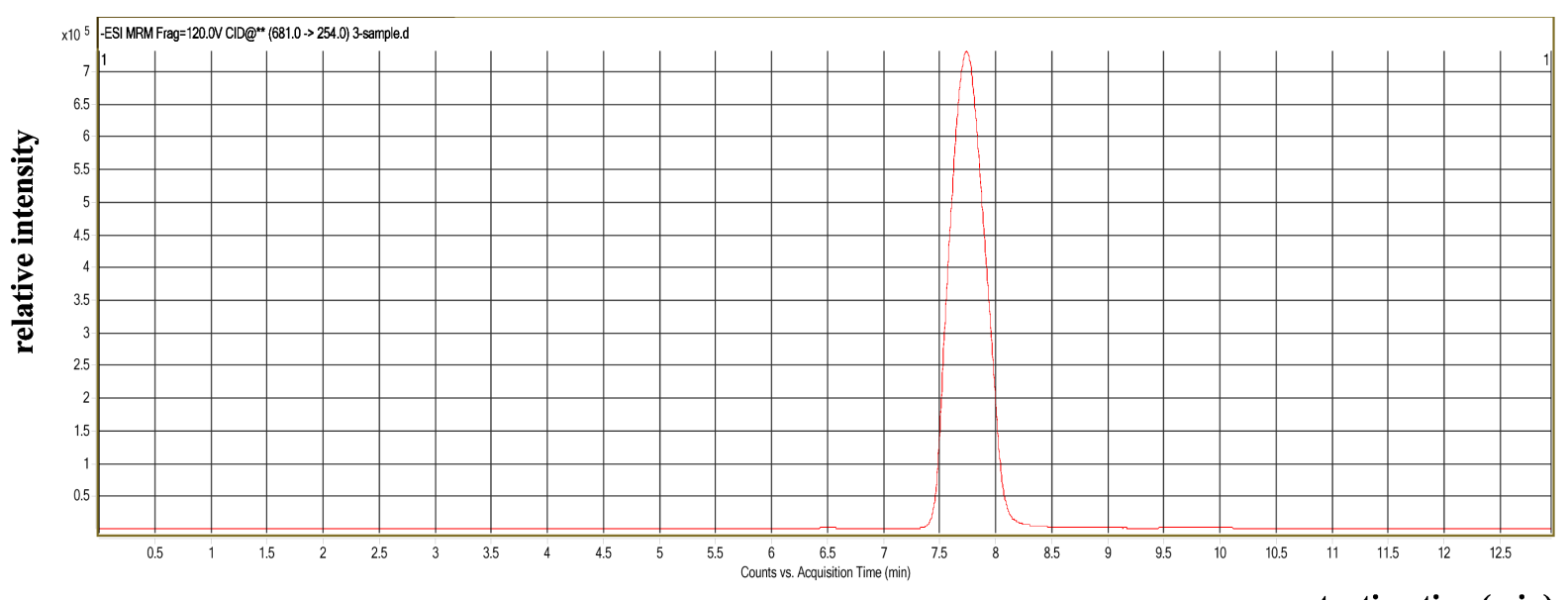

retention time(min)

Figure 3. Selected ionization chromatography of residue flubendiamide in the soil sample by MRM mode $(\mathrm{m} / \mathrm{z} 254)$.

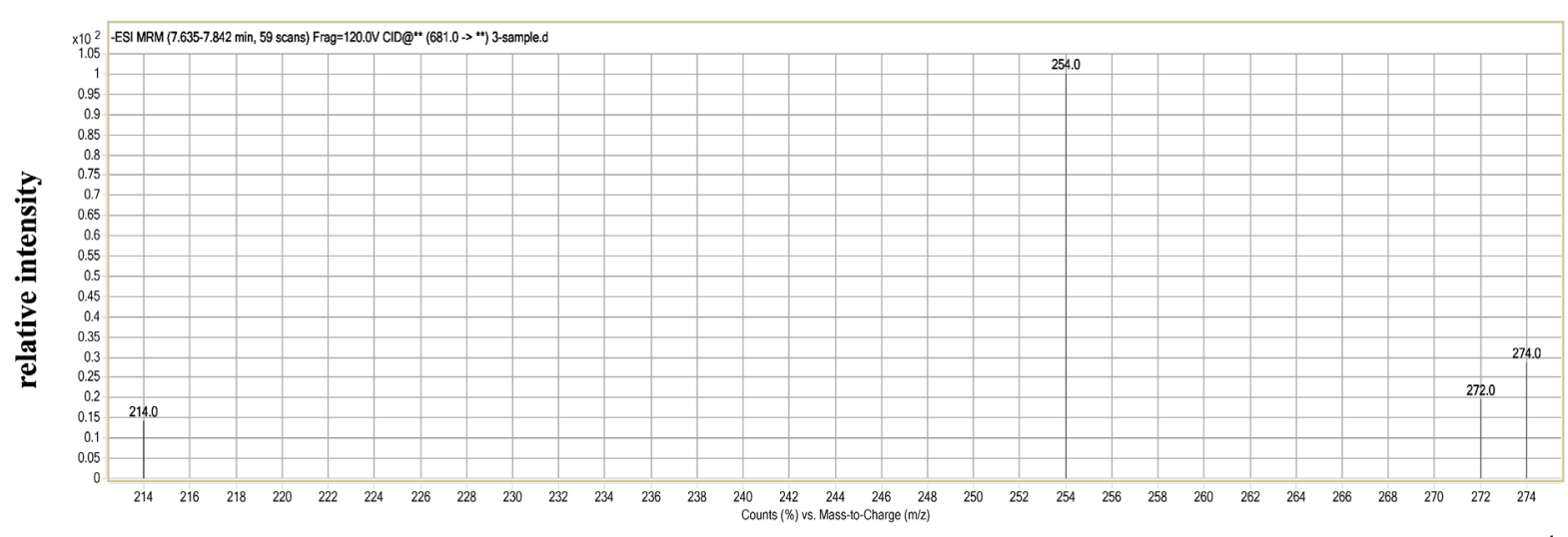

$m / z$

Figure 4. MS-MS spectrum of residue flubendiamide in the soil sample by LC-MS/MS.

Table 3. Degradation dynamics equation of flubendiamide in the soil.

\begin{tabular}{ccccc}
\hline Time (year) & Sample Location & Degradation Dynamics Equation & Correlation Coefficient & Half-Life (d) \\
\hline \multirow{2}{*}{2011} & Yangzhou & $C_{t}=1.8131 \mathrm{e}^{-0.1352 \mathrm{t}}$ & 0.9770 & 5.13 \\
& Jingzhou & $C_{t}=1.9875 \mathrm{e}^{-0.1389 \mathrm{t}}$ & 0.9804 & 4.99 \\
\multirow{2}{*}{2012} & Yangzhou & $C_{t}=2.0251 \mathrm{e}^{-0.1569 \mathrm{t}}$ & 0.9797 & 4.42 \\
& Jingzhou & $C_{t}=1.8051 \mathrm{e}^{-0.1586 \mathrm{t}}$ & 0.9863 & 4.37 \\
\hline
\end{tabular}

Table 4. Terminal residual of flubendiamide in the cabbage.

\begin{tabular}{ccccc}
\hline & \multicolumn{2}{c}{ Terminal Residual of Yangzhou $\left(\mathrm{mg} \cdot \mathrm{kg}^{-1}\right)$} & \multicolumn{2}{c}{ Terminal Residual of Jingzhou (mg $\left.\cdot \mathrm{kg}^{-1}\right)$} \\
\cline { 2 - 5 } Application Dose $\left(\mathrm{g} \cdot \mathrm{m}^{-2}\right)$ & 2011 & 2012 & 2011 & 2012 \\
\hline 0.025 & No & No & No & No \\
0.050 & 0.0393 & 0.0247 & 0.0273 & 0.0225 \\
CK & No & No & No & No \\
\hline
\end{tabular}

Note: Mean of three replicates. "No" means no flubendiamide was detected.

flubendiamide was $0.015 \mathrm{mg} \cdot \mathrm{kg}^{-1}$, which could provide high-quality results for degradation dynamics and residue analysis of flubendiamide in cabbage and soil qualitatively and quantitatively. The method is rapid, simple, highly sensitive, and can meet the requirements for analysis of active ingredients and residues. 
Table 5. Terminal residual of flubendiamide in the soil.

\begin{tabular}{ccccc}
\hline \multirow{2}{*}{ Application Dose $\left(\mathrm{g} \cdot \mathrm{m}^{-2}\right)$} & \multicolumn{2}{c}{ Terminal Residual of Yangzhou $\left(\mathrm{mg} \cdot \mathrm{kg}^{-1}\right)$} & \multicolumn{2}{c}{ Terminal Residual of Jingzhou (mg.kg $\left.{ }^{-1}\right)$} \\
\cline { 2 - 5 } & 2011 & 2012 & 2011 & 2012 \\
\hline 0.025 & No & No & No & No \\
0.050 & 0.0762 & 0.0691 & 0.0589 & 0.0475 \\
CK & No & No & No & No \\
\hline
\end{tabular}

Note: Mean of three replicates. "No” means no flubendiamide was detected.

\section{Conclusion}

In conclusion, the recoveries of flubendiamide from the cabbage and the soil were $80.70 \%-90.44 \%$ and $84.37 \%$ $94.00 \%$, respectively. Degradation dynamic equations of flubendiamide in the cabbage and soil were based on the first-order reaction dynamic equations. The half-life of the degradation of flubendiamide was 3.51 - $3.96 \mathrm{~d}$ and 3.43 - $3.87 \mathrm{~d}$ in the cabbage of Yangzhou and Jingzhou respectively. The half-life of the degradation of flubendiamide was 4.42 - $5.13 \mathrm{~d}$ and 4.37 - $4.99 \mathrm{~d}$ in the soil of Yangzhou and Jingzhou, respectively. The terminal residue of flubendiamide in the cabbage of Yangzhou and Jingzhou was $0.0247-0.0393 \mathrm{mg} \cdot \mathrm{kg}^{-1}$ and 0.0225 $0.0273 \mathrm{mg} \cdot \mathrm{kg}^{-1}$ when $20 \%$ flubendiamide WDG was applied at the using dose of $0.050 \mathrm{~g} \cdot \mathrm{m}^{-2}$. Flubendiamide should be safe if it was applied in the cabbage field at the recommended dose.

\section{Acknowledgements}

The authors would like to thank the Natural Science Foundation of Jiangsu Province (BK20130443), Social Development Science and Technology Projects of Yangzhou City, China (2012110) and Natural Science Foundation of the Jiangsu Higher Education Institutions of China (13KJB210010) for providing financial support.

\section{References}

[1] Lahm, G., Selby, T.P., Freudenberger, J.H., Stevenson, T.M., Myers, B.J., Seburyamo, G., Smith, B.K., Flexner, L., Clark, C.E. and Cordova, D. (2005) Insecticidal Anthranilic Diamides: A New Class of Potent Ryanodine Receptor Activators. Bioorganic and Medicinal Chemistry Letters, 15, 4898-4906. http://dx.doi.org/10.1016/j.bmcl.2005.08.034

[2] Li, Y., Li, M., Chai, B.S. and Liu, C.L. (2006) Flubendiamide, a New Insecticide. Pesticide, 45, 697-699.

[3] Seo, A., Tohnishi, M., Nakao, H., Furuya, T., Kodama, H., Tsubata, K., Fujioka, S., Kodama, H., Nishimatsu, T. and Hirooka, T. (2007) Flubendiamide, a New Insecticide Characterized by Its Novel Chemistry and Biology. Pest Management Science, 30, 354-360.

[4] Hoffmann, E.J., Vandervoort, C. and Wise, J.C. (2009) Curative Activity of Insecticides against Plum Curculio (Coleoptera: Curculionidae) in Tartcherries. Journal of Economic Entomology, 102, 1864-1873. http://dx.doi.org/10.1603/029.102.0517

[5] Lahm, G.P., Cordova, D. and Barry, J.D. (2009) New and Selective Ryanodine Receptor Activators for Insect Control. Bioorganic and Medicinal Chemistry Letters, 17, 4127-4133. http://dx.doi.org/10.1016/j.bmc.2009.01.018

[6] Rhainds, M. and Sadof, C. (2009) Control of Bag Worms (Lepidoptera: Psychidae) Using Contact and Soil Applied Systemic Insecticides. Journal of Economic Entomology, 102, 164-1169. http://dx.doi.org/10.1603/029.102.0339

[7] Caboni, P., Sarais, G., Angioni, A. and Singh, S.K. (2008) Liquid Chromatography-Tandem Mass Spectrometric IonSwitching Determination of Chlorantraniliprole and Flubendiamide in Fruits and Vegetables. Journal of Agricultural and Food Chemistry, 56, 7696-7699. http://dx.doi.org/10.1021/jf8014816

[8] Qin, D.M., Qi, X., Sun, Y. and Xu, Y.M. (2009) Analysis of Flubendiamide in Chinese Cabbage and Soil by Liquid Chromatography. Pesticide, 48, 755-756.

[9] Qian, M.R., Zhang, H., Wu, L.Q., Liu, F., Wang, X.Y., He, H. and Chen, Z.M. (2010) Determination of Residual Chlorantraniliprole Benzamides and Flubendiamide in the Vegetables by Liquid Chromatography-Tandem Mass Spectrometry. Analytical Chemistry, 38, 702-706.

[10] Mohapatra, S., Ahuja, A.K., Deepa, M., Sharma, D., Jagadish, G.K. and Rashmi, N. (2010) Persistence and Dissipation of Flubendiamide and Des-Iodo Flubendiamide in Cabbage (Brassica oleracea Linne) and Soil. Bulletin of Environmental Contamination and Toxicology, 85, 352-356. http://dx.doi.org/10.1007/s00128-010-0063-4

[11] Liu, J.F., Zhu, G.N., Ding, W. and Wu, H.M. (2011) Degradation Dynamics of Flubendiamide in Paddy Ecosystem by 
Liquid Chromatography-Tandem Mass Spectrometry. Pesticide Science, 13, 310-313.

[12] Paramasivam, M. and Banerjee, H. (2011) Simultaneous Determination of Flubendiamide Its Metabolite Desiodo Flubendiamide Residues in Cabbage, Tomato and Pigeon Pea by HPLC. Bulletin of Environmental Contamination and Toxicology, 87, 452-456. http://dx.doi.org/10.1007/s00128-011-0389-6

[13] Paramasivam, M. and Banerjee, H. (2013) Degradation Dynamics of Flubendiamide in Different Types of Soils. Bulletin of Environmental Contamination and Toxicology, 88, 511-514. http://dx.doi.org/10.1007/s00128-012-0552-8

[14] Paramasivam, M. and Banerjee, H. (2013) Dissipation of Flubendiamide Residues in/on Cabbage (Brassica oleracea L.). Environmental Monitoring and Assessment, 185, 1577-1581. http://dx.doi.org/10.1007/s10661-012-2652-7

[15] Liang, H.W., Li, L., Li, W., Wu, Y.J., Zhou, Z.Q. and Liu, F.M. (2011) Dissipation and Residue of Dimethomorph in Pepper and Soil under Field Conditions. Ecotoxicology and Environmental Safety, 74, 1331-1335. http://dx.doi.org/10.1016/j.ecoenv.2011.02.009

[16] Ministry of Agriculture of the People’s Republic of China (2004) Pesticide Residue Testing Criteria NY/T788-2004. China Agriculture Publishing House, Beijing.

[17] Chen, X.J., Lu, C.L., Fan, S.Q., Lu, H.B., Cui, H.R., Meng, Z.Y. and Yang, Y.Z. (2012) Determination of Residual Flubendiamide in the Cabbage by QuEChERS-Liquid Chromatography-Tandem Mass Spectrometry. Bulletin of Environmental Contamination and Toxicology, 89, 1021-1026. http://dx.doi.org/10.1007/s00128-012-0805-6

[18] Stajnbaher, D. and Zupancicc-Kralj, L. (2003) Multiresidue Method for Determination of 90 Pesticides in Fresh Fruits and Vegetables Using Solid-Phase Extraction and Gas Chromatography-Mass Spectrometry. Journal of Chromatography A, 1015, 185-198. http://dx.doi.org/10.1016/S0021-9673(03)01211-1

[19] Guardia-Rubio, M., Marchal-López, R.M., Ayora-Canada, M.J. and Ruiz-Medina, A. (2007) Determination of Pesticides in Olives by Gas Chromatography Using Different Detection Systems. Journal of Chromatography A, 1145, 195203. http://dx.doi.org/10.1016/j.chroma.2007.01.068

[20] Frenich, A.G., Plaza-Bolaños, P. and Martínez Vidal, J.L. (2008) Comparison of Tandem-in-Space and Tandem-inTime Mass Spectrometry in Gas Chromatography Determination of Pesticides: Application to Simple and Complex Food Samples. Journal of Chromatography A, 1203, 229-238. http://dx.doi.org/10.1016/j.chroma.2008.07.041

[21] Anastassiades, M., Lehotay, S.J., Stajnbaher, D. and Schenck, F.J. (2003) Fast and Easy Multiresidue Method Employing Acetonitrile Extraction/Partitioning and "Dispersive Solid-Phase Extraction" for the Determination of Pesticide Residues in Produce. Journal of AOAC International, 86, 412 -431.

[22] Paula, P., Michelangelo, A. and Dorothea, M. (2007) Analysis of Pesticide Residues Using the Quick Easy Cheap Effective Rugged and Safe (QuEChERS) Pesticide Multiresidue Method in Combination with Gas and Liquid Chromatography and Tandem Mass Spectrometric Detection. Analytical and Bioanalytical Chemistry, 389, 1697-1714. http://dx.doi.org/10.1007/s00216-007-1610-7

[23] European Norm EN 15662:2009-02 (2008) Foods of Plantorigin-Determination of Pesticide Residues Using GC-MS and/or LC-MS/MS Following Acetonitrile Extraction/Partition and Cleanup by Dispersive SPE-QuEChERS-Method. European Norm EN. 
Scientific Research Publishing (SCIRP) is one of the largest Open Access journal publishers. It is currently publishing more than 200 open access, online, peer-reviewed journals covering a wide range of academic disciplines. SCIRP serves the worldwide academic communities and contributes to the progress and application of science with its publication.

Other selected journals from SCIRP are listed as below. Submit your manuscript to us via either submit@scirp.org or Online Submission Portal.
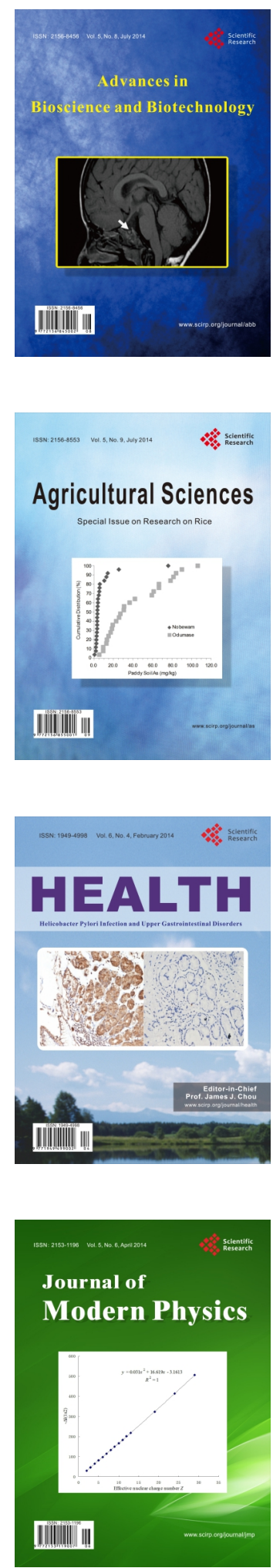
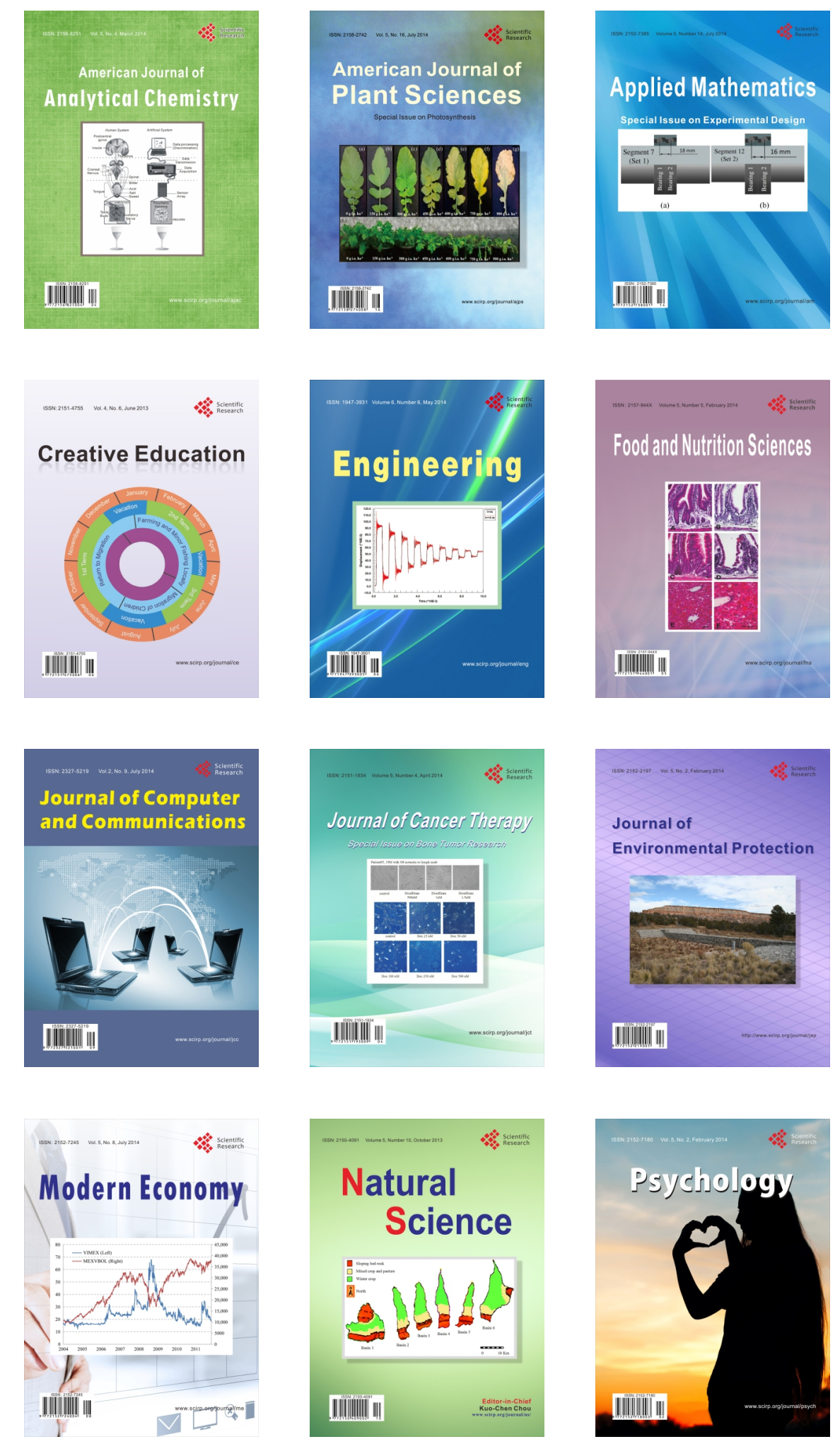